\title{
Stefan Sell and Stefan Rehart: Surgery of rheumatic diseases
}

\section{Thieme Verlag, New York-Stuttgart-Delhi-Rio de Janeiro, 2017, 170 pp, 435 III. Hardcover, EUR (D) 99.99 EUR (A) 102.80 CHF 115,00, ISBN: 978-3-13-240007-8}

\section{Pierre Kehr ${ }^{1}$}

Received: 31 October 2017 / Accepted: 17 November 2017 / Published online: 28 November 2017

๑) Springer-Verlag France SAS, part of Springer Nature 2017

\begin{abstract}
After a recall of the principles of the orthopedic rheumatology, the authors present us successively the indications and the techniques recommended for the rheumatologic affections of the hand, the wrist, the fingers, the tendons of the wrist and the hand, the elbow, the shoulder, the foot, the ankle, the hip and the spine. Each chapter is illustrated by splendid operational photographs and didactic anatomical drawings.
\end{abstract}

This true monument of the rheumatologic surgery current will have to appear in the library of the specialized surgeons, in particular of the hand and the foot, as in that of the rheumatologists regularly confronted with this invalidating pathology.

\section{Compliance with ethical standards}

Conflict of interest The author declares that they have no competing interests.
Pierre Kehr

pierre.kehr@gmail.com

1 Strasbourg, France 